\title{
Ten minutes with Luis Machado, Department Manager for Eye Casualty, Nottingham University Hospitals NHS Trust, Nottingham, UK
}

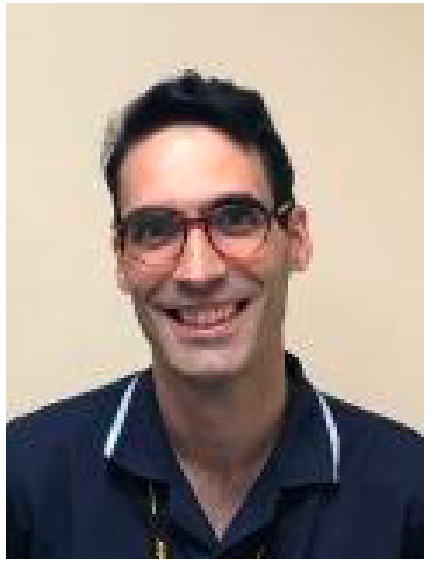

\section{WHAT ARE THE KEY LEADERSHIP MESSAGES YOU WANT TO GET OUT TO THE BMJ LEADER READERSHIP?}

Personally, the key message, with or without a pandemic, is communication. I believe it is important that staff are always aware of changes, as well as the reason behind them. This gives staff the opportunity to have ownership of those changes, and allow them to give feedback. Which leads me onto my next key message of motivation. Despite different clinical environments and different stressors of the job, it is important that my staff know that I am here to guide and support. It is imperative that I maintain a presence and stand with my staff, whether or not we are in a pandemic. Finally, it is important to be firm, but fair. Staff must always be aware that if something is not right, it must be highlighted and a solution sought, as patient safety and their safety is paramount.

\section{TELL US A LITTLE BIT ABOUT YOUR LEADERSHIP ROLE AND HOW IT IS CHANGING AS A RESULT OF THE PANDEMIC?}

My role is the Department Manager for Eye Casualty at a large teaching hospital in the East Midlands. This is my first time working in the specialty, having been in ward-based roles until this point. I oversee 22 members of staff, of which 1 is a Deputy Department Manager, 8 are nurse practitioners, 5 are staff nurses, 4 are healthcare assistants and 4 administrative staff. The Eye Casualty in the prepandemic period was exceedingly busy, with 80-100 patients visiting the department on a weekday. My role in Eye Casualty is to manage staffing, processes and patient safety. From the very beginning, my leadership role was guided by the knowledge of the staff who had worked in the department for many years, and I was very honest with them about this. I also made it clear to my team that I have an inquisitive mind, and would question a lot of the aspects of the working environment, to improve the way the department worked. With this being said, I feel my leadership style was very democratic and transformational when I first started in the department. I really encouraged my staff to take a more participative role in the decision-making process.

With the pandemic unravelling over just a few weeks, my leadership style has evolved to a more autocratic approach.

\section{Biography}

Luis Machado is the Department Manager for the Eye Casualty at Nottingham University Hospitals NHS Trust. Luis obtained his Nursing degree in 2014, in his home country of Portugal. That same year, Luis made the decision to move to the UK, where he began his career as a staff nurse on an acute Hepato-PancreatoBiliary surgical ward. In 2016, he commenced his first managerial role as Deputy Charge Nurse on a surgical admissions ward, and in 2017, wanting to further develop his leadership skills and take on a new challenge, he returned to his Hepato-Pancreato-Biliary roots, where he had started his career in the UK, as the Deputy Charge Nurse. No two days were the same in this role, and Luis thoroughly enjoyed the fast paced, challenging environment of such a specialised surgical unit.

COVID-19 has come at a time when Luis was 7 months into his current role in the ophthalmology department, a specialty in which he has no clinical background. Although this is not his first leadership and management role, he has led successful reorganisation and restructuring of the Eye Casualty clinical environment.

Lots of changes occurred over a short space of time, which meant I had to make quick, final decisions on a lot of processes within the department. For example, Eye Casualty was previously amenable to having both inpatients and relatives in the department; this had to stop with immediate effect due to capacity issues and social distancing. I knew it would be difficult for my staff on the ground to police this, particularly when having to enter dialogue with relatives. Based on Human Resources advice, I had to restructure working practices, assessing whether my staff members could continue in face-to-face roles with patients, based on their individual health and social circumstances. This introduced real challenges with the restructuring of the staff rota, which I had to turn around within 2 days, ensuring we had adequate cover for the service, while making sure my staff were not being overworked. Finally, I had to be assertive with the wider divisional management team about the role that doctors in Eye Casualty needed to have during this time, particularly with the onsite support they would have to provide if the staff I had available until 22:00 (when the department closes) on any shift, were not patient facing. As one can imagine, this was not very well received by the clinicians, given that their on calls are mainly non-residential, but eventually they understood given the unprecedented times we faced.

I do not believe in micromanaging, but as the pandemic unfolded, I had to get involved in aspects of the department I would have previously allowed my staff to manage. This was particularly evident with ensuring rules on patient flow on a dayto-day basis were strictly adhered to; particularly, the number of patients allowed in the department at any one time and insisting that only true emergency conditions be reviewed in the department. Pre-COVID-19, I would leave management of the shop floor to my daily Eye Casualty coordinator. 
Although, in the current climate, changes were often implemented without much input from my staff, I insisted that they focused on these changes as the 'beta' version, and that my door was always open to suggestions of how it could be done better. I was fully aware that this may not be the perfect way of doing things, but for now, it was all we had in the time pressured environment.

\section{WHAT EVENTS IN YOUR PAST EXPERIENCE ARE MOST INFORMING YOUR LEADERSHIP IN THIS PANDEMIC?}

My nursing training started in Portugal, where we have a very different national health system. The environment was transfixed on finding logical and profitable solutions for everything. Even as a student nurse, the level of responsibility was very high and I was expected to work alongside nurses as their colleague, rather than their student. I also had the opportunity to be the nursing representative, to act as the intermediary between the nursing students and leadership of the university and the hospital where I was based. I really feel this role helped me to develop my communication skills with peers and leaders alike, which is a skill that has been instrumental during this time (even more so than normal). I have also had nursing experience as a student in Norway, so with these experiences in different clinical environments I feel I am able to adapt to dynamic situations quickly, which has helped me a lot during the pandemic.

With my experience of fast-paced ward-based roles, you inevitably come across conflict in many different forms. It can be conflict with management, ward team members or relatives; very similar to what has occurred with the ever-evolving tide of the pandemic. I made it my goal to defuse those stressful situations so that a calm, sensible resolution could be achieved. I believe I have developed this skill purely because of this exposure. This has really helped me in the current climate with ever changing policies in the department; with strong agreeance as well as lack of consensus I had to stand firm but also instil an element of unity to ensure my team, and beyond, understood that we were fighting the common fight, and we should not be fighting among ourselves.

\section{WHAT ARE YOU FINDING THE BIGGEST CHALLENGES?}

Eye Casualty has changed so much since the start of the pandemic. We transitioned from a walk in to referral-only service to protect both staff and patients. We were so used to seeing around 100 patients a day, and now we are down to 40. I miss being that busy. Everything is organised from a managerial point of view, and this is thanks to the early multidisciplinary input. It is a little difficult for me to maintain enthusiasm on a day-to-day basis considering the reduction in our services. This is augmented further while observing how busy my acute medical and surgical colleagues are, as I know what it is like to be on those teams. Do I feel guilty? Yes, in some ways I do, and not being able to support my wider nursing colleagues (because I needed to remain focused on my own department) has played on my mind. Now, going forward, the main challenge will be if our infrastructure will cope with the new guidance on social distancing in a clinical setting, and the increase in patient numbers. I have a limited number of nurse practitioners who can have face-to-face contact with patients, and in practical terms I only have three full-time nurse practitioners, when I previously had eight. There is no movement with recruitment in the peri-COVID period and this is one aspect of the job which is daunting for me at the moment.

\section{ANY PARTICULAR SURPRISES?}

I would say the only particular surprise I have had was the lack of understanding from senior clinicians as to what my role is, even before the pandemic. I think there was a misconception that I was meant to be in Eye Casualty 100\% of the time, when in fact my role was to make sure Eye Casualty was running efficiently as close to $100 \%$ of the time as possible. It has been great that attitudes have changed and feedback has been really positive. There is now a crystal clear understanding of what my role is, and how successful it has been devoting my time to being a leader and manager, more than a nurse practitioner seeing patients.

\section{ARE YOU SEEING ANY BEHAVIOURS FROM COLLEAGUES THAT ENCOURAGE OR INSPIRE YOU?}

My staff really inspire me. They are so passionate about Eye Casualty, and always available to do extra shifts to cover sickness and self-isolation. I often have to take a step back from being a manager and wanting shifts covered, and say to them 'no, you cannot do so many shifts, you need to look after yourself'. Their dedication, even under difficult circumstances like this, is truly remarkable.

\section{HOW ARE YOU MAINTAINING KINDNESS AND COMPASSION?}

I am making an active effort to understand other people's problems and issues, particularly in these unprecedented times. I think I am approachable, sincere and try to find solutions. I am the youngest member of the team, and so my view on work and the world may be different to other staff members. I have to be cognisant of this, and how I approach issues within the department. I am a big supporter of encouraging well-being, and I have instilled this in my staff on a daily basis. I am very strict on making sure this is followed, that is, taking breaks during the day and not working too many extra shifts.

\section{ARE THERE ANY IDEAS OR READINGS THAT YOU FIND HELPFUL, FOR INSPIRATION AND SUPPORT, WHICH YOU WOULD RECOMMEND TO OTHERS?}

Honestly, I have never read a book or article on leadership. However, I did participate in some very insightful training back in 2017 for Charge Nurses in the Surgical Division, where I was able to discuss my leadership style and how I can work around the leadership styles of my colleagues. It was particularly interesting and inspirational to hear from senior colleagues who have been in leadership roles much longer than I have, how they have overcome challenges in these roles and what has and has not been successful.

To be a successful leader, I think you have to be kind by nature and have a vested interest in looking after your staff. I have used my own skill set to develop my personal style of leadership. I pride myself on being a good communicator, and this has really helped me in my leadership roles. My approach is always 'if you have nothing nice to say, don't say it at all' and 'think first, speak later'.

I have great leadership role models and mentors, particularly my current managers I work with. I have worked with one of these managers for over 5 years, and we seem to have followed each other around the National Health Service, so I have been lucky to have such great continuity in my own leadership. We have very similar managerial and leadership styles of not micromanaging, and so I emulate them in many respects. These mentors, and others, have provided me with a template to develop my own leadership style. I have essentially learnt on the 
job! However, going forward, and when time allows of course, a further education course, maybe even a Masters degree, would be something I would definitely be interested in doing to further my learning on leadership.

\section{WHAT ARE YOU LOOKING FOR FROM YOUR LEADERS?}

Leaders needs to be reasonable, understand the limitations of those working on the ground, understand the working environment of their staff, and most importantly, encourage teamwork.

Luis Machado, Michelle S Attzs

Department of Ophthalmology, Nottingham University Hospitals NHS Trust, Nottingham, UK

\section{Correspondence to}

Miss Michelle S Attzs, Department of Ophthalmology, Nottingham University Hospitals NHS Trust, Nottingham NG7 2UH, UK; michelle.attzs@gmail.com

Contributors Both authors contributed equally to the formulation of this manuscript.

Funding The authors have not declared a specific grant for this research from any funding agency in the public, commercial or not-for-profit sectors.

Competing interests None declared.
Patient consent for publication Not required.

Provenance and peer review Not commissioned; internally peer reviewed.

Data availability statement No data are available.

This article is made freely available for use in accordance with BMJ's website terms and conditions for the duration of the covid-19 pandemic or until otherwise determined by BMJ. You may use, download and print the article for any lawful, non-commercial purpose (including text and data mining) provided that all copyright notices and trade marks are retained.

(c) Author(s) (or their employer(s)) 2020. No commercial re-use. See rights and permissions. Published by BMJ.

$$
\text { D Check for updates }
$$

To cite: Machado L, Attzs MS. BMJ Leader 2020;4:257-259.

Received 5 May 2020

Revised 31 May 2020

Accepted 3 June 2020

Published Online First 16 June 2020

BMJ Leader 2020:4:257-259.

doi:10.1136/leader-2020-000284

ORCID iD

Michelle S Attzs http://orcid.org/0000-0001-6954-2121 